\title{
Immunogenetics: Novel Developments
}

\author{
Henk S.P. Garritsen ${ }^{a}$ Christoph Gassner ${ }^{b}$ \\ a Institut für Klinische Transfusionsmedizin, Städtisches Klinikum Braunschweig gGmbH, Germany \\ ${ }^{b}$ Blutspende Zürich, Leitung Forschung und Entwicklung, Qualitätskontrolle (FEQ), Stiftung Zürcher Blutspendedienst SRK DLZ, Zürich, \\ Switzerland
}

Histoincompatibility between donor and recipient is still one of the major obstacles in allogeneic hematopoietic stem cell transplantation (HSCT). Even if the donor and recipient are major histocompatibility complex(MHC)-matched, complications such as graft-versus-host disease (GVHD), poor immune function, and graft failure may occur from minor antigenic differences between donor and recipient. There are several possibilities to counteract these potential complications:

- improved HLA typing with reduction of HLA ambiguities

- increasing pools of potential donors

- development of novel approaches like cellular therapies to avoid complications after allogeneic stem cell transplantation.

The current issue of Transfusion Medicine and HemoTHERAPY is focussing on these three issues.

Gabriel et al. [1] discuss the possibilities and limitations of using next-generation sequencing (NGS) for HLA typing. One important aspect is that the growing number of HLA ambiguities could be dissolved fast by applying NGS systems in immunogenetics. The conditions under which the benefits of NGS can be used optimally are described. However, the management of significant amounts of sequencing data and the general organization of the workflow are major challenges for the immunogenetic laboratories.

HLA typing developments are an important part in the transplantation mosaic; however, availability and motivation of stem cell donors is and will remain an important issue to perform allogeneic HSCT. In two papers from Swiss and Austrian registries we have the possibility to look behind the scenes with respect to donor management and developments in acquisition of new donors. Both countries have realized centralized search coordination units for national and international searches.

In the article of Rosenmayr et al. [2] the work (and search algorithms) and outcome of the Austrian centralized search unit is described. Since January 1, 1988 the Austrian Bone Marrow Donor Registry has been the central search coordination unit. Key data show that the total number of searches performed for Austrian patients with hematologic disorders is 2,166 (1,671 adults / 495 children). With respect to efficiency: in the early years (until 1995) an unrelated donor (URD) was identified in $53,4 \%$ of the patients. Nowadays (between 2008 and 2010) 78,3\% of the URD searches were successful. Looking at indications for allogeneic stem cell transplantations, the Austrian colleagues observe a strong rise in patients with acute myeloid leukemia, myelodysplastic syndrome and lymphoma, and a marked decrease in those with chronic myeloid leukemia. This trend is also observed in Germany and Switzerland.

Nicoloso de Faveri et al. [3] present the Swiss Transfusion SRC, division Swiss Blood Stem Cells. This organization is quite similar to the Austrian organisation fulfiling 5 main tasks: registry coordination, donor searches, allocations of grafts, international collaboration, and consulting to the Federal Office of Public Health (FOPH). The organization, in this form is quite new (started in Januar 2011) and has an ambitious program of increasing the number of potential peripheral blood stem cell donors in Switzerland. Their success is documented: in the last 2 years the number of potential donors has increased by $30 \%$ ! The donors are needed because also the transplantation activity is steadily rising.

As to the third issue, development of novel approaches like cellular therapies to avoid complications after allogeneic stem cell transplantation, there is a cautionary note from Kehrmann et al. [4] concerning FoxP3 regulatory T cells. Donor $\mathrm{T}$ cells can contribute both positively and negatively to hematopoietic stem cell transplant (HSCT). Their positive role is documented by facilitating engraftment, controlling opportunistic infections, and contributing to anti-tumor immunity. Their involvement in the generation of GVHD reflects their

\section{KARGER}

Fax +497614520714

Information@Karger.de

www.karger.com (c) 2011 S. Karger GmbH, Freiburg

Accessible online at:

www.karger.com/tmh
Dr. Henk S.P. Garritsen

Institut für Klinische Transfusionsmedizin

Städtisches Klinikum Braunschweig gGmbH

Celler Straße 38, 38114 Braunschweig, Germany

Tel. +49 531595-3675, Fax -3758

h.garritsen@klinikum-braunschweig.de 
negative role. To date it is possible to discriminate donor T-cell subpopulations responsible for positive and negative effects of HSCT. These T-cell subsets can be modified or cultivated to ameliorate GVHD. FOXP3-positive regulatory $\mathrm{T}$ cells are one of these T-cell subsets and essential for maintenance of tolerance in transplantation. Their name derives from the forkhead box protein P3 (FOXP3) which is a transcription factor essential for the development and function of CD4+ CD25 $5^{\text {high }}$ regulatory T cells. The next step will be to generate functional induced Treg cells through stable expression of FOXP3. Kehrmann et al. try to induce sustained FOXP3 expression by ectopic expression of GARP in $\mathrm{T}$ helper cells. They observed that the phenotypic transformation is not reflected by Treg-specific demethylation patterns. This raises questions on the stability of engineered $\mathrm{T}$ cells for cellular therapies generated by ectopic expression of GARP.

In conclusion: a lot of novel developments but also a lot of new questions in immunogenetics!

\section{References}

1 Gabriel, C, Stabentheiner, S, Danzer, M, Pröll, J: What next? The next transit from biology to diagnostics: next generation sequencing for immunogenetics. Transfus Med Hemother 2011;38(5):308317.
Rosenmayr, A, Pointner-Prager, M, Winkler, M, Mitterschiffthaler, A, Pelzmann, B, Bozic, L, Pichler-Lurzweil, S, Tüchler, H, Fae, I, Fischer, G.F: The Austrian Bone Marrow Donor Registry: providing patients in Austria with unrelated donors for transplant - a worldwide cooperation. Transfus Med Hemother 2011;38(5):292-299.
3 Nicoloso de Faveri G, Schwabe, R, Bart, T: Swiss Blood Stem Cells: more than just a registry. Transfus Med Hemother 2011;38(5):300-307.

4 Kehrmann, J, Zeschnig, M, Buer, J, Probst-Kepper, M: GARP-induced FOXP3 expression in helper $\mathrm{T}$ cells is not associated with FOXP3 TSDR demethylation. Transfus Med Hemother 2011;38(5): 287-291. 